\title{
ENTRE FILOSOFÍA Y NO FILOSOFÍA. UN SILENCIO, UNA ESPERA, UNA CONCIENCIA
}

\author{
BETWEEN PHILOSOPHY AND NON- \\ PHILOSOPHY. A SILENCE, A WAIT, A \\ CONSCIOUSNESS
}

Ma Carmen López SAÉNZ*

UNED

Resumen: El presente trabajo intenta justificar desde la fenomenología de Husserl y Merleau-Ponty la interrelación entre filosofía y no filosofía y, con ella, la interacción del pensamiento occidental con el oriental. Para ello negaremos, en primer lugar, su condición de contrarios; posteriormente ejemplificaremos las posibilidades de sus intercambios haciendo referencia a la fenomenología y a la Escuela de Kioto, concretamente a sus respectivas concepciones de la conciencia en las que yo y no-yo no se oponen, sino que integran un campo de diferencias. La obra de M.T. Román, especialmente su último libro, actúa como hilo conductor de nuestra interpretación de la conciencia fenomenológica y del yo de Nishida dejando constancia de la importancia del «entre» para ejercer mediaciones. Una de sus formas es el silencio.

Palabras clave: Fenomenología, Escuela de Kioto, Conciencia, Ego, apertura. "Catedrática de Filosofía en el Departamento de Filosofía de la UNED. E-mail: clopez@fsof.
uned.es 
Aвstract: This paper aims to justify, using the phenomenology of Husserl and Merleau-Ponty, the interrelation between philosophy and non-philosophy and, with it, the interaction of Western and Eastern thinking. In order to do this, we will deny, in the first place, their condition of opposites; later we will exemplify the possibilities of their exchanges by referring to phenomenology and to the Kyoto School, particularly to their respective conceptions of consciousness in which I and non-I do not oppose each other, but rather are part of a field of differences. The work of M.T. Román, especially her last book, acts as the common thread of our interpretation of Nishida's phenomenological conscience and self, giving evidence of the importance of the «between» in order to establish mediations. Silence is one of its forms.

KeYwords: Phenomenology, Kyoto School, Consciousness, Ego, Openness.

\section{Merleau-Ponty: “Occidente y Oriente”. ¿Filosofía y no-filosofía?}

Maurice Merleau-Ponty (1908-1961) se interesó por lo que denominaba «inmensa literatura pensante de Oriente» y consideró que, como tal, formaba parte de la filosofía que se esfuerza por buscar la verdad en la vida humana indivisa. De ahí que la obra dirigida por él, Les Philosophes célèbres, comience con una sección titulada "El Oriente y la filosofía»; le sigue otra denominada «Los Fundadores» (Heráclito, Parménides, etc.). Esto pone de manifiesto que el fenomenólogo incluía estos saberes en la génesis del pensamiento filosófico, más concretamente, en esa tradición que nos ha legado los temas en los que seguimos pensando, así como los antagonismos que constituyen su núcleo, uno de los cuales es el de la relación entre filosofía y no-filosofía. Teniendo en cuenta todo lo que Grecia aprehendió de las culturas precedentes, resulta difícil fijar una frontera -al menos geográfica- entre lo que sea filosófico y lo que no lo sea. Si tenemos en cuenta, además, que toda filosofía se nutre de lo que no es filosofía, la delimitación se complica en un grado más alto.

Como es sabido, Hegel solo concedía dignidad filosófica a los pensamientos conceptuales; por eso trataba la sabiduría oriental como una aproximación a la filosofía y a la verdad occidentales. Su afirmación de Oriente debía ser negada y superada enseguida por encontrarse alejada de la culminación del verdadero devenir del espíritu. Merleau-Ponty se opuso a este modo de entender la dialéctica que la detenía en el saber y en el espíritu absoluto. Vio en La Crisis de Husserl 
un correctivo a este modo de entender el saber. Interpretó la declaración de Husserl contenida en esta obra, «el sueño de la filosofía como ciencia estricta ha terminado", como una constatación de que los filósofos ya no podían arrogarse la posesión del rigor conceptual, sino que tenían que contrastarlo siempre en el campo de los fenómenos, yendo «a las cosas mismas»; esto no implicaba renunciar a los conceptos, sino más bien deshacer su rigidez: «Husserl lo había comprendido: nuestro problema fundamental es abrir el concepto sin destruirlo» ${ }^{1}$ y, para ello, su continuador opta por no fijar una frontera rígida entre la filosofía y la no-filosofía. Como Husserl, continúa tematizando la experiencia, viviéndola conscientemente y entendiéndola como distancia en la proximidad del ser-enel-mundo. No le cabe duda de que lo originariamente percibido es el mundo "pero su proximidad absoluta, desde que lo examinamos y expresamos, deviene, asimismo, inexplicablemente, distancia irremediable» (Merleau-Ponty, 1964a: 23). De ahí su convicción de que lo más fecundo de Husserl es la tensión entre la actitud natural y los resultados de la reflexión, entre la experiencia efectiva y su pensamiento «adecuado» por la vía de la filosofía. De esa tensión husserliana se seguiría que las sabidurías orientales ${ }^{2}$ son saberes y pensamientos, aunque de otro tipo.

En efecto, Husserl afirma que el saber de China e India es un "puro tipo empírico antropológico» (1936: 14) de la filosofía. Es preciso entender previamente qué sea el tipo (Typus) empírico para la fenomenología. Se trata de una generalidad que no es una construcción ideal, pero está provista de elementos de sentido ya mostrados en objetos precedentes; estos elementos son sintetizados pasivamente (fundamentalmente por asociación) hasta constituir una adquisición que, posteriormente, guía nuestras percepciones, ya que crea expectativas acerca de los elementos típicos de un objeto de esta clase. El tipo indica que a la conciencia perceptiva ${ }^{3}$ sus horizontes (temporales, espaciales, etc.) ya le pre-señalan la aprehensión general de algo en cuanto «objeto», así como una determinada tipificación -a la manera de las especies- de cada nuevo objeto percibido.

\footnotetext{
1 (Merleau-Ponty 1960, 174). Todas las traducciones son de la autora a no ser de que se indique lo contrario.

2 Así las denomina T. Román, compañera que nos animó siempre a entablar diálogos con ellas y con ella (Román 2008).

3 Estas tipificaciones constituyen el hilo conductor del análisis de la percepción en Husserl 1939. Véase principalmente $\$ 83$.
} 
Mientras que los saberes orientales serían para Husserl tipos así entendidos o ejemplares históricos, Grecia constituiría el origen de la filosofía, es decir, de «el movimiento histórico de la revelación de la razón universal, como tal, “congénita” para la humanidad» (Husserl, 1936: 13-14). Por tanto, todo ser humano puede hacer renacer su participación en la razón realizando por sí mismo el acto que la reveló originariamente. Esto significa, siguiendo a MerleauPonty, que Husserl privilegia la filosofía occidental, pero lo hace «en nombre de un hecho, y para asignarle una tarea» (1960: 173). El hecho acontecido en Grecia es, como tal, histórico y, por tanto, no tiene derechos especiales en comparación con otros. Ahora bien, podemos asumirlo como fundamento de una tarea que los seres humanos dedicados a la filosofía no pueden eludir, porque han heredado la institución originaria de la filosofía y son co-portadores de su dirección; dicha tarea no consiste en describir la facticidad, sino en la "comprensión crítica de la unidad del conjunto de la historia, de nuestra historia» (Husserl, 1936: 74). Esta unidad es la intencionalidad de las filosofías precedentes que nos aproxima a la verdad de la teleología de la historia.

Ciertamente, a la filosofía le debemos algunos medios teóricos y prácticos para tomar conciencia y explorar una verdad buscada incesantemente. Lo que la diferencia de Oriente es este legado, pero solo tiene efectos en la indagación filosófica, es decir, en la asunción de la tarea de comprender los otros pensamientos a la vez que se re-examina continuamente la propia idea de la verdad, sus conceptos $\mathrm{y}$ «todas las instituciones -ciencias, capitalismo y, si se desea, complejo de Edipo- que, directa o indirectamente, se encuentran emparentadas con su filosofía, para hacer frente a la crisis que atraviesan» (Merleau-Ponty, 1960: 175). Así es como Husserl se enfrenta a la crisis de racionalidad detectada en las ciencias de su época. El único privilegio que reconoce al pensamiento occidental es haber inventado esa idea de verdad que le autoriza a comprender otras culturas y dar testimonio de sí más allá de los especímenes antropológicos, cuestionando sus propios fundamentos y tomando conciencia de que la universalidad de la razón está enraizada en cada mundo de la vida particular. La razón debe cumplirse en cada uno de ellos, no en su reducción o en su dominación. Dado que todo pensamiento forma parte del mundo vivido, todas las culturas son ejemplares empíricos y ninguna tiene derechos absolutos sobre las demás. Incluso las culturas denominadas "primitivas» han desempeñado un papel importante en la exploración de las más desarrolladas, poniendo en cuestión nuestros prejuicios y ayudando así a encontrar el verdadero sentido. Esto significa que también la filosofía debe justificar su racionalidad y debe hacerlo para superar la crisis de su idea de cientificidad, así como para relacionarse con otras culturas y saberes. Las 
sabidurías orientales, por su parte, no solo serían filosofía si consintieran, como piensa Hegel, en conceptualizar sus conocimientos, sino también si fueran capaces de asumir la tarea originaria de la filosofía y juzgaran su verdad en relación con otras experiencias de sentido.

Esta posibilidad se actualiza, desde nuestra perspectiva, en la concepción merleau-pontiana de la «institución» (Stiftung) del sentido como descentramiento y re-centramiento de los plurales elementos y dimensiones de nuestra vida desde la propia situación, por ejemplo, como movimiento hacia el pasado y, también a la inversa, como pasado reavivado hacia nosotros (Merleau-Ponty, 1968: 64-65). Este ejemplo puede extenderse a todas nuestras relaciones. En todas ellas, el sentido no es constituido por el yo, sino que el yo solo contribuye a instituirlo a la vez que él mismo se instituye. «Institución» es un proceso contingente en el que nos encontramos, pero fundador de un sentido que puede sedimentarse y reactivarse con el tiempo. Lo instituido tiene sentido sin mí, mientras que lo constituido solo tiene sentido para mí y para el yo de este instante. «Constitución [significa] institución continuada, i.e. jamás realizada. Lo instituido atraviesa su porvenir, tiene el suyo, su temporalidad; lo constituido tiene todo de mí, el que constituye (el cuerpo, el reloj)» (Merleau-Ponty, 2003: 37). Lo instituido no es, por consiguiente, un contenido de conciencia, sino el conjunto de «estos acontecimientos de una experiencia que la dotan de dimensiones duraderas, en relación con las cuales toda una serie de otras experiencias tendrán sentido, formarán una continuación pensable o una historia, o incluso acontecimientos que dejan un sentido en mí, no a título de supervivencia y de residuo, sino como llamada a una continuación, exigencia de un porvenir» (Ib.: 61).

Aplicando esta concepción, el fenomenólogo francés asegura que, aunque India y China, tienen un enorme interés como culturas, para convertirse en instituciones de sentido, necesitarían discernimiento de su verdadero sentido; ellas, por sí mismas, no nos lo dan completamente. Es necesario, por tanto, que mantengan relaciones con Occidente (como ha sido el caso de Nishida y de la Escuela de Kioto), que comprendan sus conceptos y se auto-comprendan en sus diferencias para desarrollarse; como contrapartida, las filosofías occidentales que entran en relación con ellas podrían hacer suyo su afán no dominador y aprender de ellas a establecer otras relaciones distintas de la mera anexión o de la simple indiferencia.

La filosofía no es un conjunto de saberes ya constituido; no está acabada, porque no se encuentra separada del mundo; se nutre de la no filosofía y siempre 
se dirige a ella. Como nuestra vida, como la razón, la filosofía tiene regresiones y progresiones y, por ello, «la relación entre Oriente y Occidente, como la del niño y el adulto, no es la de la ignorancia con el saber, la de la no-filosofía con la filosofía. Es mucho más sutil, admite todas las anticipaciones en Oriente» (Merleau-Ponty, 1956: 49). Tal vez la más importante es que «las filosofías de la India y de la China, han buscado, más que dominar la existencia, ser eco o resonador de nuestra relación con el ser» (Ib.: 50). Debido a ello, pueden enseñarnos a los pensadores y pensadoras occidentales a encontrar otras relaciones con el ser que no sean las de la posesión, a comprender verdaderamente nuestros orígenes, a sopesar las posibilidades que hemos clausurado decidiendo ser occidentales $\mathrm{y}$, tal vez, hasta a volver a abrirlas dejándonos educar por otros modos de orientación hacia el ser y otras maneras de pensar. Estas son algunas de las razones que justifican la inclusión merleau-pontiana de Oriente en «el museo de los filósofos célebres». No se trata de sustituir la verdad filosófica por el mito, aunque tampoco de rendirse a la triunfante post-verdad. Esas otras sabidurías nos invitan a aprender a ver de otro modo que no sea solo abriendo los ojos, «a mirar lo permanente en lo mudable y efímero» (Román, 2017: 154). Precisamente así es como la fenomenología aprehende las esencias o lo invariante, después de realizar libres variaciones imaginativas sobre lo dado.

Como K. Jaspers (1883-1969), Merleau-Ponty con su atención a Oriente quería hacer surgir la dimensión eliminada del logos cuya génesis conforma una unidad con el origen de la historia global. Además, ponía de manifiesto que la historia de la filosofía estaba integrada por una pluralidad de experiencias y de saberes. Esta fue también la clave de la obra de M. T. Román. Dialogando con ella y con la obra de Merleau-Ponty, descubrimos el interés fenomenológico de la Escuela de Kioto, formada en torno a la figura de Kitaro Nishida (1870-1945), y establecimos una aproximación comparativa entre ambos tomando como núcleo la dinámica de sus respectivas concepciones de la negatividad y la nada, ambas fundadas en una nueva lógica del lugar (Cf. López, 2018).

Enseguida nos dimos cuenta de que la dificultad para comprender estas nociones radicaba en que no eran intuiciones directas de cosas positivas, sino procesos o movimientos irreducibles al mero cambio de lugar, desapropiaciones y aperturas a la alteridad. En su decurso, no solo hay cambio, sino también relación y, para que esta se produzca, es imprescindible un lugar no espacial, un «entre» (Zwischen). Gracias a él es posible asimismo la filosofía comparada. La que nosotros descubrimos entre la fenomenología y la Escuela de Kioto exigió un esfuerzo crítico y auto-crítico. Nishida y Merleau-Ponty lo realizaron hasta el punto de 
comprender que la conciencia se formaba y expresaba diacríticamente, en la identidad de las contradicciones y en sus relaciones con el mundo y con el ser.

Nishida desarrolló su pensamiento confrontándolo con la historia de la filosofía occidental en la que se educó. Por lo que respecta a Merleau-Ponty, Oriente le impactó por su anti-dualismo y por su potencialidad para trascender las dicotomías arraigadas en nuestra tradición occidental y describir la realidad relacional sin establecer jerarquías. Su filosofía, tan relacional como anti-dualista, no pretendía disolver las diferencias, sino comprender en su seno y manteniendo su tensión en busca de lo común ${ }^{4}$. Estaba convencido de que el intercambio con las sabidurías orientales no solo era otra modalidad de apertura a lo diverso, sino lo que nos permitía comprendernos a nosotros mismos como filósofos. De esa reflexión se sigue que el diálogo con Oriente no solo nos abre a lo otro, a lo diferente y exótico, sino que nos permite reencontrarnos con lo que creíamos más propio, desapropiarnos y reconocer que la génesis de Occidente no es sino la de su relación con otras culturas. Así se fragua también la experiencia de cada ser humano: en contacto con otros saberes y con las experiencias de los otros para, más tarde, concebir la suya como una variante iluminada por ellas. El primer paso para ello es reconocer que la filosofía no surge de la nada, sino en relación con otras culturas, otros saberes e incluso lo irreflexivo, buscando una «unidad indirecta» (Merleau-Ponty, 1956: 42) que franquee el hiato entre Oriente y Occidente y entre religión y filosofía, porque «no hay una filosofía que contenga todas las filosofías; la filosofía entera se halla, en ciertos momentos, en cada una. Pues la verdad, el todo, está más allá desde el principio -pero como tarea a cumplir» (Merleau-Ponty, 1956: 37). Esa tarea es el a priori histórico descubierto por Husserl; se realiza mediante la interrogación filosófica de todas las tradiciones que sean capaces de hacernos pensar.

De la misma manera que cada filosofía es necesaria para las otras, los saberes antiguos, las obras de otras tradiciones distintas, si hacen pensar, forman parte de nuestra propia interrogación, que es fundamentalmente lo que caracteriza a la actividad filosófica. Por tanto, ni las sabidurías orientales son la no filosofía absoluta ni la filosofía es un producto de Occidente. No hay dualismo y subordinación de uno de sus términos a otro, sino movimiento de relación recíproca.

Veamos a continuación, cómo puede concretarse esa participación entre la fenomenología y la Escuela de Kioto.

4 Véase mi trabajo de 2012, principalmente, pp. 26-48. 


\section{Fenomenología y Escuela de Kioto. Intuición y apertura del yo}

Se ha dicho que el budismo en Japón se caracteriza por emplear conceptos intuitivos y concretos, debido a su aceptación del mundo fenoménico como absoluto (Lanzaco, 2000: 285). Explorar ese mundo implica, para la fenomenología, estudiar los actos de conciencia, siendo la intuición uno de ellos, así como un primer nivel de cualquier relación. Ahora bien ¿en qué consiste esa intuición? Tanto para la fenomenología como para la Escuela de Kioto es activa y directa. Nishida está especialmente interesado en la intuición intelectual ("categorial», diría la fenomenología), es decir, en la de los objetos ideales u objetos que, según él, solo pueden ser conocidos dialécticamente. Este es uno de los rasgos que diferencia su intuición de la de Husserl; otro es que no solo la considera una operación del sujeto, sino incluso un acontecimiento en el que todavía no hay diferenciaciones, una conciencia de la realidad última tal y como es. Desde su perspectiva, no es la conciencia la que intuye, sino que la intuición trasciende todas las operaciones de la conciencia. Las discrepancias con la intuición husserliana parecen ser tantas como las similitudes con la intuición bergsoniana, a pesar de que el propio Nishida declara, contra esta última, que no puede ser denominada filosofía: los contenidos filosóficos pueden derivar de la intuición, pero la filosofía solo surge cuando la intuición toma la forma del conocimiento conceptual $^{5}$. El filósofo japonés se somete así a la concepción de la filosofía occidental de Hegel a la que hemos hecho referencia. Esto no es de extrañar si tenemos en cuenta que Nishida se formó en ella, pero la desarrolló sobre la experiencia de la meditación Zen (Ogawa, 1978: 208) que coloca la actividad a la misma distancia que la pasividad; en cambio, la filosofía occidental privilegia la actividad del sujeto. Debemos señalar, no obstante, que la fenomenología genética considera la pasividad como integrante de la actividad. Asimismo, el Zen la entiende como otro modo de operar que consiste en alcanzar un estado de neutralidad o "término medio absoluto" (Suzuki, 1986: 313), cuya evolución filosófica origina el no-ego y, finalmente, el vacío de toda sustancia, gracias al cual podemos describir la existencia no como un agregado de entes, sino como vida relacional y múltiple. En este sentido, la vacuidad es realidad fundamental, puesto que precede a todas las diferenciaciones. ¿Cómo podremos, entonces, pensarla? El Zen sólo dice que «los pensamientos han de despertarse sin morar en parte alguna» (Ib.: 349), pues no son productos del falso yo, sino del verdadero, que es

5 (Nishida 1923, 668). He desarrollado el paso de la experiencia pura nishidiana a la intuición activa en mi trabajo, 2018, 498 y ss. 
la unión sujeto-objeto. Dilatando así sus fronteras hacia el mundo el yo alcanza su máxima expresión auto-formándose en él; además, particulariza lo mundano. A nuestro juicio, esta es una concepción crítica tanto de la subjetividad moderna como de esa subjetividad horizontal típica de Occidente que pone al sujeto frente al mundo-objeto. En contraste con ella, encontramos en la Escuela de Kioto una concepción vertical del sujeto-mundo, ya que el pensamiento del vacío en el que se inspira no pierde al yo, sino que lo vacía de sí y lo implica en las cosas para que se encuentre auténticamente. Esto exige una verdadera conversión del pensamiento reflexivo tal y como lo entendemos en Occidente, una "metanoia» (Del Arco, 2004: 232), que constituye el verdadero sentido de la filosofía que puede extraerse del budismo. No obstante, consideramos que este término debería entenderse aquí en su sentido originario, como un recomenzar de otro modo.

Volviendo a la intuición nishidiana, ahora nos damos cuenta de que, si bien exige un pensamiento conceptual, también requiere una des-sustancialización del yo encargado de forjar esos conceptos. Nishida la concibe como un vaciado de yo para prestar atención a la vida. Husserl, por su parte, rehabilita el mundo de la vida (Lebenswelt) como fundamento de la ciencia y de la vida trascendental. Lo que tienen en común es que ambos se enfrentan al psicologismo, es decir, a la creencia de que los pensamientos sean objetos que están en la conciencia como en un contenedor.

Además de la intuición y, en general, de los datos inmediatos de la conciencia, otro de los atractivos de la fenomenología para la Escuela de Kioto es su concepción del yo no sustancial, sino trascendental, su detallada descripción de sus actos y de las virtualidades de la conciencia. Sin embargo, la conciencia intencional fenomenológica, la inmanencia de toda trascendencia, no puede parangonarse con el no-yo nishidiano. No obstante, si bien Husserl busca la permanencia en un ego articulador del sentido disperso, Merleau-Ponty renuncia, como Nishida, al ego puro. Sus respectivas re-conceptuaciones del vacío como espacio de apertura del individuo concuerdan con la vacuidad no nihilista que caracteriza a los miembros de la Escuela de Kioto. El yo extático de Nishida, por ejemplo, y el sujeto corporal abierto al mundo de Merleau-Ponty no solo presuponen una desposesión de lo que el individuo creía más propio, sino también un rechazo de la lógica abstracta que prioriza al sujeto como mera res cogitans. Nishida la sustituirá por su lógica del lugar; Merleau-Ponty rehabilitará el espacio, secularmente despreciado por la filosofía, principalmente el espacio topológico ${ }^{6}$.

6 Véase el desarrollo de este tema en mi trabajo 2018: 501-503. 
Los dos se interesan por un espacio que no es ni cuantitativo, ni euclidiano, ni una condición formal de posibilidad, sino un «lugar» subjetivo-objetivo, la sede de la verdadera negatividad, «el pliegue» o el punto intermedio (entre-deux) en el que se produce la inversión de lo interior y lo exterior, de lo invisible y lo visible, lo que Husserl denominaba Wahrnehmungsbereit (presto a ser percibido) (Merleau-Ponty, 1964a: 317-8), el cuerpo que abre a una experiencia que se está haciendo. El mejor ejemplo de la misma es el hueco entre las dos manos que se tocan y que no es algo que deba llenarse, sino el gozne y la diferenciación entre lo que toca y lo tocado. Esta articulación no solo es obra de la actividad de la conciencia, sino también del movimiento de flexión desde lo exterior a lo interior y a la inversa, de ese movimiento que es verdadera re-flexión de un ser que sabe de sí porque siente y es sentido:

Hay una rigurosa simultaneidad (en ningún sentido, causalidad) entre el cuerpo y la reflexión [...] el cuerpo sensible y sentiente no es el doble de una reflexión ya acabada; es la reflexión figurada, el dentro de un fuera [...] Pues la reflexión es la venida a sí del Ser, Selbstung, a través de un sentir (Merleau-Ponty, 1995: 340).

El cuerpo es el paradigma de esta re-flexión que no sobrevuela las cosas, sino que se genera replegando lo interno en lo externo e incorporando el afuera al movimiento que se produce dentro. De este modo, es capaz de sentirse sintiendo, y de ser sentido como sentiente. Este trabajo de negatividad no anula lo positivo, sino que «lo reconstruye más allá de sus limitaciones», es el «resorte» (Merleau-Ponty, 1968: 79) del pensamiento dialéctico, la trascendencia o el ser a distancia. En palabras de F. Cheng, sinólogo y miembro de la academia francesa, "la verdadera transcendencia, paradójicamente, está en el "entre"» (2007: 23), es decir, en una relación que eleva y supera a cada ser, que concibe negativamente la subjetividad, porque necesita al mundo como el ser necesita un no-ser que lo circunscriba.

Nishida comparte esta dialéctica, así como la búsqueda merleau-pontiana de un intervalo entre la corporalidad y la conciencia. En su opinión, la existencia humana no gravita en torno al alma, sino al cuerpo, ya que, gracias a él, el ser humano construye su medio y su historia. Como para la fenomenología, el cuerpo no es algo meramente objetivo, sino incursión en la génesis del mundo. 
Siguiendo a Husserl, Nishida ve en el cuerpo la personalidad expresada. Sin la interacción del cuerpo con la conciencia, no sería posible ni siquiera la nada sobre la que se instaura la intuición, porque la voluntad, que es el nivel más originario de la conciencia, no se activaría ${ }^{7}$. Esta nada $(m u)$ a la que se refiere Nishida es «lo último pre-conceptual desde donde surgen todas las entidades diferenciadas» (Wilkinson, 2009: 84).

Merleau-Ponty aspira a llegar a ese nivel originario de lo ante-predicativo. La fenomenología, en general, considera necesaria para ello la epojé: una desconexión de la actitud natural que implica un «despertar» a la actitud filosófica, así como un despertar del olvido del yo en el que nos han sumido el naturalismo y el positivismo. En un sentido análogo, Nishida se ha referido al auto-despertar de lo individual que desempeńa un rol similar al de la auto-conciencia occidental. Sin embargo, la conciencia despierta (jikaku) no es algo vuelto hacia sí, sino la experiencia pura e inmediata. De ahí que el pensador japonés «sitúe» dicho auto-despertar más allá del yo, en el lugar (basho). Desarrolla una lógica del mismo como base de su filosofía y de la inteligibilidad del vacío, que este filósofo comprende como el predicado de todos los predicados. Se sigue de ello que la conciencia no es sujeto, sino predicado: es la vida de la conciencia de la que soy consciente. El yo deviene auto-unificación de un campo de conciencia del que surge la actividad predicativa. Se trata de la conciencia de sí, no tanto como auto-conciencia, sino como apertura a lo otro y como posterior retorno a sí misma, como unidad entre yo y no-yo que permite que algo aparezca.

La lógica del basho requiere esa negación del yo para evitar caer en nuevas objetivaciones, y un auto-despertar del sí mismo al lugar en el que se sitúa y relaciona con todo lo demás. Previamente, ha debido vaciarse de sustancia y de proyección yóica. Así parece haberlo comprendido también Merleau-Ponty cuando concluye que "el problema yo-otro es un problema occidental» (1964a: 274), y solo muestra que la fórmula dual es insuficiente, pues lo que hay es un campo y polimorfismo. Los roles no se oponen, sino que se complementan y entrelazan sin anular las diferencias, pues yo y otro surgen de algo más primordial que les une y separa, a la vez, como una bisagra: la carne (chair) del cuerpo y la carne del mundo.

En Nishida hay ecos de esta desapropiación fenomenológica del yo para abrirse a otros y regresar a sí mismo, aunque no como un ego trascendental, sino

7 Un estudio detallado de esta cuestión, en Oshima 1993. 
como un ser social, que se reconoce como individuo justamente porque se opone a los otros para formar un mundo común (Nishida, 2006: 35). Además de su infinita relacionalidad, el individuo nishidiano es una unidad independiente, una perspectiva del mundo con sus propios valores. Se halla muy cerca de la mónada con ventanas de Husserl: «Cada acto consciente es una mónada existencial de la propia auto-reflexión del mundo. Nuestra auto-conciencia no tiene lugar en un sí mismo meramente cerrado, sin ventanas» (Nishida, 1987: 53).

Como la mónada, cada individuo, es un universal concreto, es decir, está determinado por lo universal y, al mismo tiempo, lo determina concretándolo. Merleau-Ponty diría que cada persona estiliza el mundo deformándolo coherentemente desde su propia situación; es una identidad lateral ${ }^{8}$. En ambos filósofos, no obstante, el universal concreto no es una idea, como en Hegel, sino lo individual como auto-determinación de la nada absoluta (Nishida) o como ser-en-en-el-mundo (Merleau-Ponty); el primero es, desde nuestra óptica, formal, mientras que el segundo es verdaderamente existencial. Es cierto que el formalismo nishidiano desaparece cuando dejamos de entender al individuo como una determinación noética, para abordarlo como sí mismo personal y como relación yo-tú. Nishida se ocupa de esta relación personal sobre la base de aquel que, en diálogo con el tú, se convierte en una conciencia inmediata de la unidad del sujeto y del objeto. Esta conciencia permite que los fenómenos hablen por sí mismos, ya que es conciencia de la experiencia pura. Su unidad negativa es la razón, que funciona como conocimiento de la realidad y como voluntad moral.

A nuestro modo de ver, no basta con establecer formalmente un universal concreto que contenga el principio de individuación y equipararlo a una mediación; tampoco es suficiente igualar la mediación con la interacción. La única mediación considerada por Nishida es la auto-negación del sí mismo que, al vaciarse de yo, descubre un fondo desfondado. Sigue siendo voluntarista afirmar con Nishida que «el acto de mediación es la voluntad en lo universal que engloba el auto-despertar» (Tremblay, 1999a: 67).

A diferencia de la voluntad, la reflexión exige mediación si no quiere ser mero reflejo de lo dado. Sin embargo, la reflexión husserliana sobre el acto de la conciencia también presenta un importante dilema: no puede eludir la división entre un yo que cumple la reflexión y otro reflexionado. A diferencia

8 Véase sobre ello mi trabajo, 2007. 
de él, el Zen comprende la reflexión como vacío que solo se corresponde con la experiencia originaria (Urerfahrung) fenomenológica, la cual comienza a adquirir sentido en la síntesis temporal y en la asociación pasiva. Lo que Nishida nos dice es que el yo desde su propio fondo, que lleva en sí al tú, se intuye activamente volviéndose hacia el otro absoluto. Por la mediación de este, el sí mismo se autodespierta convirtiéndose en un verdadero sí mismo personal. Su auto-despertar se inicia con la auto-negación del yo que deja ser al otro sin objetivarlo. El carácter fundamental de la existencia o Samsara es ese despertar a lo otro de sí. En cualquier caso, ni el sí mismo ni el absoluto son sustantivos, sino direcciones, sentidos, e incluso verdades, pues la verdad exige descartar al yo subjetivo para unirlo incluso con la naturaleza (Nishida, 1995: 123). La identidad contradictoria entre el sí y el absoluto no significa simplemente imperfección de lo relativo, sino negación del absoluto (Nishida, 1999: 110). Dicha identidad se niega para despertar como sí mismo trascendente, pues la trascendencia no está fuera del sujeto, sino en su profundidad, que constituye «el lugar de la identidad contradictoria» (Nishida, 2006: 69). $M u$ es esa nada de profundidad infinita, no meramente un vacío. Análogamente, Merleau-Ponty ha subrayado el topos de la profundidad como la primera -no la tercera- dimensión, la dimensión de la simultaneidad, porque es relacionalidad: un interior gestándose que solo puede ilustrarse como matriz polimorfa del ser carnal, el Ineinander (Merleau-Ponty, 1996: 362). La filosofía no es ni conciencia ni síntesis de identificación, sino saber de ese uno en otro (Ineinander), de las implicaciones paradójicas entre naturaleza y espíritu. Así es el ser carnal: un ser de profundidades, latencias y presentaciones de ciertas ausencias. Su paradoja constitutiva está en todo lo visible, incluso en la actividad de filosofar, pues "filosofía verdadera es no filosofía, entrar en la profundidad de la Erfahrung» (Ib.: 312). La profundidad no es una propiedad del sujeto, sino la dimensionalidad del ser. La filosofía accede a ella si no renuncia a comprender críticamente la no filosofía, si entiende que la subjetividad es negatividad, no como en Hegel porque niegue la objetividad, sino porque necesita al mundo, como el ser necesita un no-ser que lo circunscriba.

Nishida considera que esa matriz desde la que se destaca la persona y el mundo es el basho en el que ambos se intercambian: «uno mismo existe como la auto-determinación del mundo activo en el que dentro es fuera y fuera es dentro" (Nishida, 2012: 134-5). Una intención semejante habita en la hiperdialéctica de Merleau-Ponty entre lo real y lo posible, esa dialéctica crítica que se querella contra la detención de la dialéctica hegeliana; a diferencia de esta, 
aquella no produce síntesis absolutas, sino síntesis de transición entre lo universal compartido y lo reactivado por cada subjetividad'.

El basho de la nada abarca las diversas dimensiones temporales y lo individual, de modo que "lo eterno está aquí y ahora» (Nishida, 2006: 73). Todas las cosas pasan, pero no en vano, porque se recogen en la eternidad, en ese presente absoluto que siempre está en curso. El concepto merleau-pontiano de hueco ( creux) es análogo a esa nada. Lo entendemos como esa concavidad que acoge, como una pausa y un detenerse del sujeto que le obliga a mantener cierta distancia en la proximidad (Merleau-Ponty, 1960: 32). Se trata de una distancia interior intrínseca al pensamiento, al deseo, al vivir. Gracias a ella, es posible aprehender el presente, no como una dimensión del tiempo, sino como un medio englobante (Merleau-Ponty, 1964a: 249), cuya trascendencia conecta el pasado con el futuro.

Por otra parte, si concebimos la nada en términos merleau-pontianos, como creux o como lo intocable que deja ser y articula las diferencias desde la profundidad, la intuición actuante nishidiana se comprende como la pasividad de la actividad. El entrelazamiento de ambas determina una aprehensión de la realidad por la que esta deja de ser el resultado de un juego de espejos y recupera su estatuto ontológico y dinámico. De un modo similar, Nishida piensa que el sentido de algo se debe a la unificación de sus partes y a la oposición de las mismas. A diferencia de la constitución husserliana, que es actividad del yo, la unificación es pasiva y activa a la vez: "Una verdadera pasividad absoluta da lugar a un verdadero dinamismo absoluto» ${ }^{10}$. La experiencia real es este dinamismo cuyo ser es la interrelación y su única actividad el universo (Nishida, 2006: 103). Por ello, el mundo no es diferente de la unidad de nuestra conciencia (Ib.: 106). De nuevo, la solución nishidiana parece detenerse en la anonimidad.

9 Dialéctica es «cohesión global y primordial de un campo de experiencias donde cada acontecimiento abre una visión sobre los demás [...] Es un pensamiento que no constituye el todo, sino que está situado en el todo» (Merleau-Ponty, 1991, 298).

10 Nishida, 2006, 91. Sería interesante comparar esta concepción con el carácter diacrítico del significado e incluso de la carne en Merleau-Ponty. 


\section{Visibilidad: lo visible y lo invisible del yo}

En Lo Visible y lo Invisible, Merleau-Ponty se acerca a esta actitud y comprende al «yo» como «una presencia para sí que es ausencia de sí» (1964a: 303). Se refiere a esa ausencia como a un creux o espacio vital que se hace en mí -yo no soy su agente- cuando el presente deja de pasar y es retenido. Este vacío no es, como la nada de Sartre, un agujero en el $\operatorname{ser}^{11}$, sino el hueco en el que se despliegan las múltiples dimensiones existenciales cuyas fronteras están más allá de la densidad del ser y de la nada; su modo de ser es el de esas cavidades del sentido, un invisible que no es lo contrario de lo visible, sino su raíz y su virtualidad. Eso es la carne en la ontología merleau-pontiana: ontogénesis del ser, no sustancia.

En Nishida no encontramos este término. No obstante, a diferencia de Husserl que se ha centrado en el cuerpo propio, el pensador nipón ha subrayado su visibilidad, entendida como «su comunidad» (Stevens, 2008: 279) o como un ver más amplio que el del vidente aislado. Ha reparado en la ambigüedad de que este sea, a la vez, visible y vidente, objeto y sujeto. Desde su óptica, el cuerpo es la condición de dicha ambigüedad. Adelanta así al último Merleau-Ponty, que huye de los residuos subjetivistas, todavía presentes en su concepción del cuerposujeto de Fenomenología de la Percepción, subsumiéndolo en la carne o visibilidad. $\mathrm{Su}$ propiedad fundamental es la reversibilidad entre lo visible y lo invisible. Se trata de un movimiento que trabaja la materia en el interior y que, a la inversa, profundiza en lo que proviene de lo exterior.

La carne no es un en-sí, sino que su ser contiene su negación, entendida como un vacío requerido por la relación generadora entre el sí mismo y el mundo; este no es un objeto; es visible, porque es materialidad y, al mismo

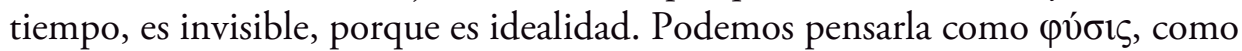
ser dinámico, únicamente descriptible mediante términos auxiliares como «quiasmo», «bisagra», «entrelazamiento»; con ellos, se insiste en que la carne no es solo el medio en el que se localizan las sensaciones, sino la profundidad. Ella acompaña a toda manifestación, incluso presenta lo invisible, que no es algo positivo, sino otra dimensión de la visibilidad. Lo invisible "está allí sin ser objeto, es la trascendencia pura, sin máscara óntica. Y los propios "visibles",

11 En Sartre, la nada es algo de la conciencia que la separa de ella misma, un "agujero de ser”, como la libertad. El surgimiento de esta requiere una doble néantisation: de su ser y del ser en medio (milieu) del cual es. (Sartre, 1947: 566). 
a fin de cuentas, están también centrados en un núcleo de ausencia» (MerleauPonty, 1964a: 282-3); este "núcleo» no carece de fundamento, sino que expresa el «surgimiento de una soberanía (Hoheit) que sostiene desde arriba» (Ib.: 303), y no es sino la nada que viene al mundo. La nada no es contraria al ser-en-elmundo, pero tampoco es él. A nuestro modo de ver, es similar a la inminencia de la reversibilidad de la carne, a la virtualidad de lo visible para devenir tangible, y a la del vidente para tocar. Este carácter perentorio y nunca complemente realizado de la reversibilidad evita la disolución de las particularidades. Presupone una distancia, una negatividad, entendida como el hueco por el que hay cosas y, entre ellas, fisuras, auto-negaciones del yo, por las que la diferencia atraviesa la inmanencia del cuerpo hasta alcanzar el interior de su exterior, porque "nuestro cuerpo no es fuera si no es dentro» (Merleau-Ponty, 1964a: 97), pues procede del movimiento centrífugo y centrípeto de la carne. Esta no es del cuerpo, sino, al contrario, hay una carne del cuerpo como hay una carne del mundo. Sus movimientos producen desplazamientos de sentido en toda dación de sentido. $\mathrm{Ni}$ aquellos ni esta tienen su origen en la sola conciencia, sino en el cuerpo, que desempeña un papel «centrífugo» siempre en relación con otro "centrípeto» inconcebible sin la donación del mundo (Dillon 1989: 146).

Como el fenomenólogo francés, Nishida ha destacado el carácter creativo de este dinamismo que, desde su perspectiva, no es la carne, sino el sí mismo confrontado con el absoluto, trascendiéndose a sí mismo hacia fuera y, a la vez, hacia adentro (2006: 88). A nuestro juicio, lo que los diferencia es que Merleau-Ponty corporeiza e individualiza este movimiento; distingue la existencia personal de la pre-personal o anónima de la carne. Esta última es la generalidad compartida por la persona con el mundo y los otros, el fondo del que se destaca la «figura» singular. Nishida, en cambio, a pesar de su insistencia en el individuo, no abandona la anonimidad, pues entiende que cada personalidad es una forma particular de una realidad única que «se manifiesta según las circunstancias» (1995: 179). Dicha personalidad exige la auto-negación del yo para dejar paso al sí mismo (jiko) (Tremblay, 2007: 19).

Una vez producida la auto-negación y la transición al sí mismo, es posible alcanzar el bien supremo: la fusión del sí mismo con la verdadera realidad. La personalidad es la fuerza por la que esto se logra. La unidad de la personalidad es el bien, pero este es motivado por la fuerza de la conciencia (Nishida, 1995: 179), cuya unidad procede de una actividad sin agente, en la que no solo no hay distinción de sujeto-objeto, sino que tampoco hay fronteras entre conocimientosentimiento-volición. ¿Cómo se gesta y desarrolla esta actividad sin yo? Y. Yuasa 
la ha definido así: «actuar, sin explicitar quién actúa, saber sin explicitar quién sabe y mirar sin explicitar quién mira» ${ }^{12}$. Ahora bien, esto no sería una acción sin agente, sin voluntad y decisión; simplemente omitiríamos todo esto en nuestra descripción de la acción. Siguiendo a Nishida, sería una acción en relación mutua con la intuición, de la misma manera que lo que da forma está unido a lo formado. De ahí que el filósofo nipón hable de «intuición actuante» y no de una recepción de impresiones que simplemente afectan o de una síntesis posterior de las mismas.

Como en Husserl, esta intuición no es un objeto meramente psíquico, sino un acto de la conciencia. Nishida no repara, sin embargo, en las modalizaciones husserlianas de los actos. Por eso, en su opinión, la misma clase de actividad caracteriza a la intuición y al pensar; ambos reciben sensaciones, aprehenden algo y sintetizan las impresiones. Husserl, en cambio, no solo reconocía la posibilidad de síntesis activas del yo, sino también la de síntesis pasivas constituidas por la temporalidad y por la asociación. La pasividad pre-dadora suministra la materia para las síntesis activas (Husserl, 1929a: 112), es decir, los juicios y todos los actos espontáneos del yo, la vida del espíritu. Nishida, en cambio, insiste en que incluso el sí mismo individual debe cesar para convertirse en centro de conciencia y de unificación en el seno de un centro más profundo. En este sentido, se acerca más a Merleau-Ponty, el cual no solo circunscribe, como Husserl, la pasividad a la afección del yo que motiva sus actos. Esto sería pasivismo subordinado al activismo, cuando lo que él quiere es sondear la pasividad para romper con otro de los dualismos que definen la metafísica de Occidente: el de la pasividad y la actividad.

Aun cuando se ha subrayado el paralelismo entre la concepción nishidiana de la intuición del sí mismo en la nada con la re(con)ducción fenomenológica a la correlación noético-noemática (Stevens, 2008: 273), lo cierto es que Nishida la trasciende hasta llegar a un nivel más fundamental que el de la conciencia reflexiva, a un sí profundo erigido sobre el basho de la nada absoluta. Esta última -no el sujeto- es el fundamento de la correlación nishidiana. En ese «lugar», los hechos se determinan sin necesidad de un sujeto cognoscente o actuante, porque no son contenidos de la conciencia, sino "la escena del mundo de los hechos» (Sylvain, 2003: 48).

12 Citado por Kuwano, 1990, 85. 
Esta importante diferencia hace que, a pesar de su valoración de la des-sustancialización del sujeto y la crítica del objetivismo de Husserl, el filósofo japonés considere que todavía piensa teoréticamente. Pretende superarlo recurriendo al basho de la nada absoluta desde el que se comprenden unidos el sujeto constituyente y los modos de constitución, pues el basho los excede si son tomados por separado. En cambio, el mundo y el sí se fundan en la nada absoluta. Recordemos que esta no tiene un sentido nihilista, sino operante, dado que funciona por auto-negación: desvelando la apertura del yo a lo otro y auto-despertando al sí mismo al tú, que se determina trascendiendo su identidad objetiva, negándose como ego fundador y abriéndose a su auto-identidad contradictoria. Solo así -no como reducción al ego trascendental-, puede pensarse la re(con)ducción nishidiana de la experiencia pura. No basta con vaciar al yo de su condición de objeto; es preciso hacerse nada radical, convirtiendo la propia actividad en invisibilidad. Desde esta postura, ¿cómo encontraremos la distancia necesaria para diferenciar y unificar la actividad cognitiva, afectiva y volitiva a la que aspira Nishida? La diferenciación sujeto-objeto como la experiencia de lo que unifica se debe a la auto-división de lo originario, pero esta solo significa que el sentido de la experiencia pura se distancia de ella para unificarse de modo inmediato en la conciencia superior o Logos. Esto atenta contra la intencionalidad fenomenológica de la conciencia dirigida también a lo otro, pero separada de ello. En palabras del propio Nishida, el sujeto intencional se disuelve en apariencias: «la aparición del mundo no es un momento de la conciencia intencional, sino un giro topológico del mundo» (Stevens, 2008: 279), porque la conciencia solo es parte de un campo y el mundo se ve desde el interior, no sobrevolándolo. Esta opinión es compartida por Gurwitsch (1957) y Merleau-Ponty, conciliadores ambos de la fenomenología de Husserl y de la Gestalttheorie. En palabras de este último, "el yo es solo otro integrante del campo; no es él quien comprende, sino la vida que se expresa y, así, nos permite ver y dejar ver» (1969: 81).

A diferencia de Husserl, mantienen que los datos de la sensación no están «animados» por los actos de la conciencia, sino por el propio movimiento (figural) de la Gestalt perceptiva que se estructura por sí misma, sin necesidad de posicionarse. A pesar de que Nishida no acepta la intencionalidad representativa, admite la intencionalidad operante, desarrollada por Merleau-Ponty como intencionalidad corporal (Cf. López, 2017), una intencionalidad motriz que no es un acto de la conciencia, sino la vida que le subyace. El propio Husserl asegura que en la actitud natural «la intencionalidad viviente (lebendige) me lleva, prescribe, determina desde el punto de vista práctico todo mi comportamiento, incluso mi pensamiento natural» (1929b: 242). Nishida haría suya esta intencionalidad 
que forma parte de la intencionalidad total, que no solo es representativa, sino también viviente y operante.

\section{La exploración de la conciencia y silencio}

Estamos convencidos de que la última obra de M.T. Roman, La exploración de la conciencia, aspira asimismo a esa intencionalidad total. Tal vez por eso su libro comienza y termina del mismo modo: interesándose por la totalidad, por el «objeto» in-objetivable e ilimitable de la filosofía que es el universo. Como diría Ortega, el filósofo no sabe nada de su «objeto», porque es el todo, el universo. Al filosofar, por tanto, se embarca rumbo a lo desconocido, a lo que no puede objetivizarse. No solo en ello la autora se acerca a la fenomenología, sino también en su methodos, profundamente filosófico y opuesto a todo metodologismo. Consiste en la apertura al propio asombro (Román, 2017: 16). Este es el sentido que E. Fink y Merleau-Ponty otorgan a la epojé, ese umbral de entrada a la fenomenología. La entienden como ruptura con la familiaridad del mundo, como extrañamiento para volver luego a un universo lleno de sentido. Siguiendo a estos fenomenólogos, uno de los resultados de la reducción fenomenológica es la comprensión de que el movimiento de regreso al sí mismo está como dividido por el movimiento inverso que suscita. Por eso, en la VI Meditación Cartesiana, Fink no solo acepta que la actitud natural sea un punto de partida para la fenomenología, sino también que la reducción solo la sobrepasa para volver nuevamente a ella en respuesta a la mundanización de la actividad fenomenologizante, la cual se funda en «la tendencia de todo filosofar a la comunicación, cuya fuente más profunda procede de la unidad "metafísica" de toda vida trascendental» (1988: 109-110). Se está refiriendo a una unidad ontológica más que gnoseológica que impulsa a la filosofía a envolver la actitud natural en la trascendental. Esta implicación explica el carácter incompleto que la re(con)ducción al sujeto trascendental presenta para Merleau-Ponty.

Esta unidad buscada por Fink se suma a la intencionalidad total, reivindicada también por Merleau-Ponty, a su filosofía relacional y al holismo del comportamiento, a su movimiento revelado en una cuasi-síntesis corporal cuya mejor

plasmación es la síntesis operativa del esquema corporal, una "síntesis de existencia» (Merleau-Ponty, 1996: 83) o síntesis vivida en una composición lateral, 
a diferencia de la intelectual o frontal. Aquella es posible porque lo que la realiza ya está en esa síntesis, en el fondo de toda praxis que es el esquema corporal que da cuenta de nuestra relación con el mundo. Esta depende tanto de la motricidad exploratoria como de la actitud del cuerpo que nos ancla en el mundo para abrirnos a todo lo otro que afecta y hasta instituye al yo.

El mismo sentido tiene la exploración de la conciencia que T. Román lleva a cabo como un movimiento sin telos. Esa ausencia explica que la obra carezca de definiciones y de conclusiones. Siguiendo a Jung, la autora no se propone explicar, porque esto es lo que hace una teoría científica, «intento efímero de explicar hechos y no una verdad eterna» (Jung citado por Román, 2017: 387). Ni siquiera pretende comprender; solo ver globalmente, ejercitar el pensamiento holístico al que constantemente hace referencia, un pensamiento que no es obra de la conciencia aislada, pero que contribuye a esclarecerla. Sus constantes investigaciones muestran que no es la conciencia la que arroja luz sobre aquello que nos disponemos a conocer, sino que lo psíquico, lo espiritual y el mundo irradian por todas partes.

De ahí que no erremos al considerar que fuera partidaria de esa intencionalidad motriz, operante y pre-temática que, sin embargo, no es absolutamente inconsciente, porque acompańa siempre a nuestra conciencia del mundo. En las últimas obras de Merleau-Ponty esta intencionalidad deviene relación originaria entre lo instituyente y lo instituido con objeto de buscar su unión en su fuente, no en el término intencional. Ahí halla incluso una intencionalidad del sueño que permite comprender la intención total que envuelve todas las intenciones parciales, una intención existencial o un proyecto de mundo. La intención originaria despierta con la reactivación, que es un acto de reflexión, pero, tal y como la entiende Merleau-Ponty, no consiste en retirarse del mundo para fundamentarlo en la unidad de la conciencia, sino en distender los hilos intencionales que nos mundanizan para tomar conciencia de nuestra trascendencia hacia lo otro.

Este fenómenologo y Nishida están emparentados con la exploración de la conciencia de la que es autora T. Román. Su investigación es tan holística que no renuncia a ninguna disciplina, obra o sabiduría. No se somete a la cronología ni claudica ante la especialización y la fragmentación que caracteriza a nuestra sociedad del conocimiento. No rehúye las aportaciones científicas, pero sabe, como la fenomenología, que las ciencias fácticas han «intentado siempre eliminar de su descripción del mundo todo lo subjetivo» (Román, 2017: 76). Escribe «intentado», porque no cree que la afectividad, los recuerdos, proyectos 
y sentimientos puedan reducirse a la actividad neuronal. De modo similar a la crítica fenomenológica al naturalismo, se opone a que la conciencia sea un simple fenómeno biológico; es más, reacciona contra el tono categórico de este tipo de afirmaciones o eslóganes y, en cambio, se abre a todo tipo de saberes más humildes, a la exploración activa que nunca descansa en el suelo del dogmatismo. Por eso, no solo por su formación o por su interés por Jung, indaga hasta en los sueños, - "metáforas vivas"-, a modo de llaves que abren puertas de universos alternativos, paradójicos $\ldots »^{13}$, en los que la imaginación convive con la razón, el mundo interno con el externo y la pasividad con la actividad. La fenomenología ha reflexionado como ninguna otra corriente filosófica actual sobre estas interrelaciones, y sobre el sueño, incluso el que parece más pobre en contenidos: el sueño sin sueños ${ }^{14}$. Como ella, T. Román explora todas las experiencias de la conciencia, especialmente las no ordinarias, lo que en filosofía llamamos experiencias-límite, esas en las que el yo amenaza con disolverse.

De la misma manera que la filosofía comparada se guía por ese holismo que mantiene las diferencias, el establecimiento de diálogos entre pensadores que nunca conversaron puede ayudar a comprender mejor sus pensamientos e incluso la eficacia de sus impensados ${ }^{15}$, que no son sus contrarios, sino como el forro de lo pensado y expresado. Indican cierto exceso del pensar. Gracias a ellos, podemos reflexionar sobre el horizonte de cada existencia y «componer en nuestro pensamiento lo que en nuestra vida forma un todo» (Merleau-Ponty, 1960: 224). Esto que a la lógica binaria puede parecerle absurdo, no lo es ni para la fenomenología anti-dualista de Merleau-Ponty, ni para la lógica predicativa de Nishida en la que se basa tanto su noción de «individuo» como la de «vacuidad» (sûnyatâ). Dialogar, como sabemos, no solo es intercambiar palabras, sino también escuchar; por tanto, dilucidar las relaciones entre el sentido, el silencio y la expresión. El silencio es constitutivo de toda palabra hablante, no solo porque la escucha es imprescindible para ella, sino porque encarna el momento de pasividad y recepción que es capaz de desencadenar cualquier afección y acción. El silencio como pausa entre palabras emitidas o espacios en blanco en la escritura garantiza, además, la inteligibilidad del discurso.

13 (Román, 2017: 88). Remito al lector interesado en la metáfora como lenguaje indirecto para llegar al ser, a mi trabajo de 2016.

14 Husserl equipara este sueńo al "sueño eterno» (2008, 337-338). Véase mi trabajo de 2015, concretamente, su apartado "Fenomenología del sueño", pp. 175-182.

15 «Pensar no es poseer objetos de pensamiento, es circunscribir por ellos un dominio que está por pensar» (Merleau-Ponty 1960, 202). 
T. Román no era ajena a la importancia decisiva de este. Su exploración de la conciencia es una interrogación por la realidad y un reconocimiento de que está determinada -para bien y para mal- por categorías lingüísticas (2017: 39). La fenomenología es de esta misma opinión; lejos de considerar que el lenguaje sea auto-referencial, investiga su relación con la expresión del sentido; en palabras de Merleau-Ponty,

El lenguaje es una vida, es nuestra vida y la vida de las cosas. Esto no significa que el lenguaje se apodere de la vida y se la reserve: ¿qué habría que decir si no hubiera más que cosas dichas? El error de los filósofos semánticos consiste en clausurar el lenguaje como si solo hablara de sí mismo, cuando en realidad vive del silencio (Merleau-Ponty, 1969: 167).

El silencio al que se refiere este filósofo es significativo e incluso podríamos decir que "habla», ya que, por un lado, permite que las palabras se articulen en sus intervalos y gracias a sus pausas; por otro lado, la percepción y los gestos expresan sentidos. Es preciso acentuar que el silencio que sigue al lenguaje no es idéntico al que le precede, puesto que la lengua y las culturas, una vez ejercitadas y sedimentadas, esperan tácitamente su reactivación y la sustentan. El silencio del que se toma conciencia no es idéntico al que simplemente está ahí; no es experiencia muda, sino que se ha filtrado por sus intersticios y ha pasado a formar parte de ella; a la inversa, también la experiencia se ha enriquecido con el lenguaje. Según T. Román, «el silencio no es la antítesis de la palabra, es el receptáculo donde se asienta la misma» (2012: 60). Análogamente a lo invisible, que no es lo opuesto a lo visible, sino su raíz, el silencio no es la negación absoluta de lo pronunciado.

Merleau-Ponty se ayuda del carácter diacrítico de los signos (Saussure) para dar nombre a este intercambio entre el mutismo de los orígenes y el lenguaje. Extiende las relaciones diacríticas entre los signos al movimiento carnal de la reversibilidad entre interioridad y la exterioridad. En sus últimas obras, el lenguaje ya no deriva directamente de la expresión de la experiencia, pues siempre estamos ya en el lenguaje. Por eso, irá más allá de Saussure y atribuirá un sentido ontológico a la relación diacrítica. Siguiendo a Heidegger, pondrá de relieve la dimensión ontológica del lenguaje. A diferencia de él, lo inscribirá en una ontología carnal que envuelve todas nuestras relaciones con los otros y con el 
mundo. El concepto clave de dicha ontología es la carne que, como hemos visto, no es sustancia, sino reversibilidad, ahora entre palabra y silencio y también entre significado-significante, porque no son contrarios, sino que se implican; así, la lengua silenciosa posibilita el habla mientras esta la reactiva. Por su parte, el silencio no es una pasividad amorfa; está estructurado como un conjunto de deformaciones coherentes de los significados sedimentados y de las intenciones desde las que se destaca el habla. El silencio también es un signo y, por relación con los otros signos, «habla», aunque no fónicamente; de ahí que, sin las pausas, sin los espacios en blanco, no pueda haber sentido global. Análogamente, sin intervalos o huecos, no es posible ninguna relación diacrítica.

Por ello Merleau-Ponty vincula sus investigaciones lingüísticas con la búsqueda de un cogito tácito, de un lenguaje del silencio que nos envuelve por doquier $\mathrm{y}$ en el que se funda el logos reflexivo. En una nota titulada precisamente "cogito tácito", se percata de que este es imposible, porque para pensar, en el sentido de ver y de sentir, como para hacer la reducción o volver a la inmanencia de la conciencia, se precisan palabras y, con ellas, se necesita "que yo constituya a la conciencia constituyente» (1964a: 224-5). No habría, por tanto, una conciencia pura de sí a la que más tarde se le diera el nombre de "conciencia». La conciencia no es constituyente de todo lo otro, no es la inmanencia que explica toda trascendencia: ya viene "constituida» por las palabras. Para decirlo con más precisión, como el cuerpo en el que se encarna, es instituyente e instituida, una actividad en una pasividad, una apropiación y una desapropiación de sí y de eso a lo que se dirige. El silencio no solo es un vacío entre las mismas; tiene una dimensión activa, dado que es un detenerse, una espera, un silencio ${ }^{16}$ constitutivo de la palabra que no solo ha sido ya hablada, sino que continúa hablando, es decir, de la parole parlante.

El silencio es el horizonte del habla y el mundo al que interrogamos, la presencia (mundo percibido) de una ausencia (intención significativa). Es tan necesario como la epojé para crear cierta discontinuidad en la continuidad de la cadena de palabras y frases que forman parte del discurso. No obstante, a diferencia de la epojé, no es una prerrogativa del sujeto; antes bien, es apertura al mundo tal como lo reencontramos, es decir, forma parte de la percepción interna a la vida, que es a la vez «ser espontáneo (cosa) y ser-sí ("sujeto")» (Merleau-Ponty, 1964a: 247). El fenomenólogo escribe entre comillas «sujeto», porque no se

${ }_{16}$ Merleau-Ponty, 1960, 32. Hemos estudiado la importancia del silencio en el habla en 2006, 32, 37, 41 y 43 . 
refiere a un sustrato, sino al movimiento, que es el núcleo común del sujeto y del objeto. Dicho movimiento es el «serpenteo» del que hablaba Bergson, interpretado por su compatriota como «modulación del ser en el mundo» o como percepción «haciéndose en las cosas» (Ibidem) y cuyo sentido se instituye en el movimiento constitutivamente inacabado de su expresión, en sus silencios y apelaciones a su continuación.

La generalidad del sujeto corporal merleau-pontiano y la universalidad concreta del individuo nishidiano presuponen una auto-negación y una apertura a lo otro no solo receptiva, sino también responsiva y creativa. Las tres son cruciales para la expresión, porque el yo y el mundo están entrelazados, y, por consiguiente, la expresión no es mero producto de una individualidad. Esto es todavía más evidente en la expresión artística.

Como es sabido, en el arte japonés predomina lo sensorial, «se revela el mundo para ser sentido y vivido directamente» (Luca de Tena, 2008: 9), pues el acto mental como el expresivo son actividades constitutivas por las que la una forma a la realidad unificadora de la otra. La rehabilitación merleau-pontiana de lo sensible tiene el mismo propósito: expresar lo sentido para sentir más reflexivamente. Sin embargo, esa reflexión, como hemos visto, no es una proyección subjetiva, sino la ontogénesis de lo interior en lo exterior, y viceversa. Para que este movimiento no se agote en una coincidencia absoluta entre ambos niveles, es preciso tener en cuenta los huecos que median entre ellos.

Si, como acabamos de ver, el silencio crea cierta discontinuidad en la continuidad del fluir y, así permite detenerse y pensar, Nishida concibe la mediación expresiva como reanudación, como "continuidad de la discontinuidad» (Zavala, 1992: 49), entendiendo por "continuidad» la determinación mutua entre persona y persona, que es el mundo de la expresión. La expresión, por tanto, unifica lo que está atomizado y, así, expresa su sentido articulado. No es el yo quien tiene la clave del mismo, pero tampoco el no-yo. Como T. Román declara citando a Mello, «El silencio no es la ausencia de sonido, sino la ausencia de ego» (2017: 143). Sin embargo, surge cuando vuelvo sobre mí, cuando profundizo en mi interior, en las entrańas -diría Zambrano- en las que arraiga el sentir, esa morada del corazón generadora de profundidad ${ }^{17}$.

17 (Zambrano, 2008, 68). Hemos establecido una comparación entre este ser de profundidades y la carne (Chair) merleau-pontiana en nuestro estudio de 2013a, pp. 122 y ss.) 
Así es como Merleau-Ponty justifica la inclusión de las sabidurías orientales en su obra Los filósofos célebres, aunque solo como «muestras para que el lector pueda discernir la sorda contribución de Oriente a la filosofía» (1960: 176). La denomina "sorda» porque no se plasma en conceptos, y porque es una influencia secreta, no explicitada y, sin embargo, real.

\section{Conclusiones}

Nuestro ejercicio de fenomenología comparada entre Nishida y MerleauPonty de la mano de la filósofa y compañera que aquí homenajeamos ha puesto de manifiesto la riqueza surgida de sus respectivas indagaciones sobre la conciencia, una conciencia que está más allá de la nada y del ser, porque los tres pensadores han trascendido los dualismos tradicionales y la lógica abstracta con objeto de reconducir la razón a sus raíces vitales, donde no está separada de la sensibilidad, de los sentimientos ni de las emociones.

Han mostrado el error de considerar la racionalidad como intelección opuesta a los sentimientos; ni estos son exclusivamente naturales, ni las palabras meramente convencionales; antes bien, ambos son, en la terminología de Merleau-Ponty, instituciones de sentido, es decir, resultados de decisiones culturales sobre lo natural. Para ilustrarlo, el fenomenólogo se ha referido a las diferencias entre las mímicas japonesas y occidentales que expresan emociones: aquellas no incluían el beso -Merleau-Ponty escribe esto en 1945- para mostrar amor; además, el japonés colérico sonríe, mientras que el occidental se crispa. De ahí se sigue que los gestos no son signos naturales, sino modos diversos de acoger corporalmente las situaciones que se han formado en un entrenamiento simultáneo del cuerpo y del mundo en la emoción (1945: 220).

Nishida se adelantó a esta denuncia de la adscripción de los sentimientos a la naturaleza y a la asociación de la razón con la mente. Dado que esta forma una unidad con el cuerpo, es absurdo separarlas para estudiar sus efectuaciones. Por ello, definió el sentimiento emocional como un fenómeno mental cuya esencia es la sensación (1978: 223). Consideraba la cultura japonesa como una cultura del sentimiento, pero sin entenderlo psicológicamente, sino «como forma de lo 
que no tiene forma» ${ }^{18}$. El sentimiento es la expresión de la personalidad, siendo esta «una unidad dinámica de actos» (Ib.: 225). Tal unidad es la verdadera individualidad, «aparece en el momento en que destruimos la subjetividad conceptual» (Ib.: 244) y dejamos un «lugar» para la afectividad y la voluntad creadora. El sí mismo libre crea dirigiéndose al mundo como su expresión, no como un objeto de dominio. Con sus concepciones topológicas del espacio, Nishida y MerleauPonty lo consiguen, mientras visibilizan la nada como modo de actividad de la pasividad. Ella es la contrapartida convexa del espacio negativo y es tan real como el espacio positivo. En efecto, la nada nishidiana y el creux merleau-pontiano son negativos fecundos con los que pone nombre y manifiestan lo invisible que también forma parte de la visibilidad. Así reflexionan sobre el movimiento de la existencia.

La experiencia pura nishidiana, en tanto actividad unificadora sin agente se identifica con su expresión. Incluso el sí mismo se determina expresándose en el mundo. Nos preguntábamos cómo puede expresarse dicha experiencia siendo anónima y muda. Nishida acaba reconociendo que el acto de expresión no escapa completamente a las relaciones con el yo consciente y sentencia: «Ver el verdadero sí debe implicar perder el sí» (Nishida, 1999: 95), es decir, despertar a sí mismo es desapropiarse de yo, dejar de concebirlo como un ente puramente racional y rescatar las múltiples dimensiones de su vida en coexistencia.

En nuestra opinión, no es suficiente olvidarse del yo para encontrar al otro, para conocer y, sobre todo, para amar; no basta con abrirse a los otros dejando que «una fuerza incomprensible» (Nishida, 1995: 227-8) obre sola para asimilar conocimiento y amor. Hay que dejar huecos para que la relacionalidad no acabe en indiferencia y la actividad en absoluta pasividad, pero también llenarlos tomando decisiones, siguiendo metas comunes y racionales. La experiencia pura es tan insuficiente como la razón pura ${ }^{19}$. Ciertamente, Nishida y Merleau-Ponty las han trascendido con sus filosofías del compromiso y la comunicación. Ambos

18 Cf. Zavala, 1992, 316. Hemos visto que, en Merleau-Ponty, la forma la proporciona la expresión que incluye la del sentimiento, aunque no se reduce a él.

19 Aunque no puedo desarrollar aquí este asunto, la fenomenología material de M. Henry adolece de los mismos inconvenientes dada su similitud con la propuesta de Nishida; es más, su concepción de la vida como subjetividad absoluta (experiencia interior de los vivientes) y auto-afección (Henry, 1990, 212, 222) se aleja de la acentuación nishidiana de la acción en el mundo, así como de la distancia en la proximidad y la diferenciación merleau-pontiana: "La vida se auto-afecta inmediatamente sin el intervalo de Diferencia alguna" (Henry 1990, 217). 
han aceptado la necesidad de ampliar la racionalidad y rescatar sus dimensiones colonizadas por la razón dominante. Sin embargo, la solución del primero de salir de la propia lógica hasta comprender el pensamiento como auto-alumbramiento, como renacer a otra dimensión, nos parece vaga. Podemos hacerlo como ejercicio de auto-descentramiento, pero no sacrificar por entero nuestra lógica a otra, pues esto sería tan reduccionista como subordinar las otras cosmovisiones a la nuestra. Más bien, resulta necesario comprender que la experiencia es impuramente carnal y que está llena de mediaciones.

De la misma manera que los pensamientos no son objetos psíquicos, sino que proceden de los impensados, los aistheta no son cosas que estén en alguna parte. Se destacan desde un fondo que todos compartimos, estilizándolo. Para ello es indispensable una distancia, una detención, porque huecos y pausas hacen posible el sentido y, en general, la manifestación de lo virtual. Gracias a ellos, Nishida y Merleau-Ponty superan los dualismos sin disolver las diferencias, sino manteniéndolas en tensión buscando lo común, el «entre», que no es un nuevo ente, sino el vacío como centro de nuestro transitar, así como la condición de posibilidad para que algo surja.

Estas filosofías han calado en nosotros porque han buscado lo universal en la concreción, en la identidad absolutamente contradictoria del individuo que nace y muere en un mundo que es nirvana y samsara, que puede ser experimentado contradictoriamente. Así es como Nishida articula su concepción del Zen con la filosofía en un mundo en el que todos los individuos surgen y retornan a la realidad última sin forma. El auto-despertar a lo que no es yo y el olvido del propio interés nos permiten sentir, porque el sentimiento no es solo una sensación subjetiva, sino "la condición fundamental del establecimiento de la conciencia misma» (Nishida, 1973: 14). Una vez establecida, no rompe para siempre con el sentir del que ha nacido ni con sus horizontes mundanos y temporales; tendría que comprender su carácter situado, corporal, y ensanchar sus relaciones mediante sus actos. Así, como decía Bergson refiriéndose a la percepción: «nos irradiamos bastante más allá de nuestro cuerpo: llegamos hasta las estrellas» (1912: 16).

\section{Referencias}

Bergson, H. " (conferencia pronunciada en 1912) (2009). "El alma y el cuerpo", en El alma y el cuerpo. El cerebro y el pensamiento: una ilusión filosófica. Madrid: Encuentro, pp. 15-45. 
Cheng, F (2007). Cinco meditaciones sobre la belleza. Madrid: Siruela.

Del Arco, J (2004). "La Escuela Filosófica de Kioto como paradigma para una reflexión intercultural”. Arbor, 705, pp. 229-246.

Dillon, M. (1989). Merleau-Ponty's Ontology. Bloomington: Indiana University Press

Fink, E. (1988). VI. Cartesianische Meditation. Teil 1. Dordrecht: Kluwer.

Gurwitsch, A. (1957). Théorie du champ de la conscience. Paris: Desclée de Brouwer.

Henre, M. (1990) (2009). Fenomenología material. Madrid: Encuentro.

Husserl, E (1929a) (1963). Cartesianische Meditationen. Husserliana I. Den Haag: M. Nijhoff.

- (1929b) (1992). Formale und Transzendentale Logik. Gesammelte Schriften 7. Hamburg: Felix Meiner Verlag.

- (1936) (1976). Die Krisis der Europäischen Wissenschaften und die transzendentale Phänomenologie. Husserliana VI. Den Haag: M. Nijhoff.

- (1939) (1948). Erfahrung und Urteil. Untersuchungen zur Genealogie der Logik. Hamburg: Claassen and Goverts.

— (2008). DIE LEBENSWELT. AUSLEGUNGEN DER VORGEGEBENEN WELT UND IHRER KONSTITUTION. Husserliana XXXIX. Dordrecht: Springer.

Kuwano, M. (I990). EL KI EN LA FILOSOFÍA DE YUASA. LA UNIDAD CORPÓREO ESPIRITUAL COMO CLAVE ANTROPOLÓGICA DE LA APERTURA PERSONAL A LA TRASCENDENCIA. Barcelona: Universidad Ramon Llull.

Lanzaco, F (2000). Introducción a la cultura Japonesa. Pensamiento y religión. Valladolid: Universidad.

López SÁenz, Ma C (2000). El arte como racionalidad liberadora. Madrid: UNED.

- (2006). "La Parole as a Gesture of the Originating Differentiation", en Penas, B. López, Ma C. (eds.) Interculturalism. Between Identity and Diversity. Nueva York: Peter Lang, pp. 27-46.

- (2007). "Identidad lateral. Un concepto de la fenomenología" in Berceo n o 153, 97-129.

- (2012). "Universalidad existencial (M. Merleau-Ponty) frente al relativismo cultural (C. Lévi-Strauss)“, en López Sáenz, Ma C., Díaz, J. M. (editores) Racionalidad y relativismo. En el laberinto de la diversidad. Madrid: Biblioteca Nueva, pp. 19-108.

-(2013a). Dos filosofias del sentir. M. Merleau-Ponty y M. Zambrano. Perspectiva fenomenológica. Editorial Académica española.

-(2015)."De la intersubjetividad a los fenómenos que dejan ir al mundo. Fenomenología y literatura”, en Investigaciones Fenomenológicas monográfico 6, pp. 153-184. 
- (2016). "Ricoeur y Merleau-Ponty. Ontología de la metáfora", en AA.VV. Con Paul Ricoeur. Espacios de interpelación. Madrid: Dykinson, pp. 299-377.

- (2017). "Intencionalidad operante en la existencia”, en Sylla, B. Borges, I. Lópcasanova, M. (Orgs.) Fenomenologia VI, Intencionalidade e Cuidado. Rio de Janeiro: Via Verita, pp. 79-119.

(2018)."An Approach to Comparative Phenomenology: Nishida's Place of Nothingness and Merleau-Ponty's Negativity". Philosophy East and West, Forthcoming in Vol. 68/2 April.

LuCa de tena, M (2008). La presencia de lo ausente. Universidad de Salamanca.

Merleau-Ponty, M. (1945). Phénoménologie de la Perception, Paris: Gallimard.

— (Dir.) (1956). Les Philosophes célèbres [2006. Edición ampliada]. Les Philosophes de l' Antiquité au XXe siècle. Paris: Librairie Générale Française.

— (1960). Signes. Paris: Gallimard.

— (1969). La Prose du monde. Paris: Gallimard.

- (1964a). Le Visible et l'Invisible. Paris: Gallimard.

- (1968). Résumés de cours. (Collège de France 1952-1960). Paris: Gallimard.

- (1991). Les aventures de la dialectique. Paris: Gallimard.

- (1995). La Nature. Notes du Cours du Collège de France. Paris: Seuil.

- (1996). Notes de Cours au Collège de France 1958-9 et 1960-1. Paris: Gallimard.

- (2000). Parcours deux 1951-1960. Lagrasse : Verdier.

- (2003). L'institution dans l'histoire personnelle et publique. Le problème de la passivité. Le sommeil, l'inconscient, la mémoire. Notes de Cours au Collège de France (1954-1955), Paris: Belin.

Nishida, K (1923). "Tetsugaku” [Philosophy] in Tetsugaku jiten [Dictionary of Philosophy], Tokyo: Iwanami. Citado en Standford Encyclopedia of Philosophy. http:// plato.stanford.edu/entries/nishida-kitaro/

- (1973). Art and Morality. Honolulu: University Press of Hawaii.

- (1978). "Affective feeling", Nitta, Y. Tatematsu, H. (eds.) Japanese Phenomenology. Analecta Husserliana v. 8. Drodrecht: Reidel publishing, pp. 223-247.

- (1987). Last Writings: Nothingness and the Religious Worldview. Honolulu: University of Hawai Press.

- (1995). Indagación del bien. Barcelona: Gedisa.

- (1999). "Logique du lieu et vision religieuse du monde". Revue Philosophique de Louvain 1, pp. 96-112.

- (2006). Pensar desde la nada. Ensayos de filosofía oriental. Salamanca: Sígueme. 
- (2012). Place and Dialectic. Two Essays. New York: Oxford University Press.

Ogaba, t (1978). "The Kyoto School of Philosophy and Phenomenology", Nitta, Y. Tatematsu, h. (eds.) Japanese Phenomenology. Analecta Husserliana, vol. 8. Drodrecht: Reidel publishing, pp. 207-221.

Oshima, H (1993). "La logique chez Nishida Kitaro". Cipango. Cahiers d'études Japonaises 2, pp. 125-138.

Roman, M. T. (2008). Sabidurías orientales de la Antigüedad. Madrid: Alianza.

- (20 I 2). "Reflexiones sobre el silencio y el lenguaje a la luz de Oriente y Occidente", Daimon 56, pp. 53-65.

- (20 I7). La exploración de la conciencia. En Oriente y Occidente. Barcelona: Kairós.

Sartre, J.P. (1947). L'être et le néant. Paris: Gallimard.

Sylvain, I. (2003). "Basho et individu chez Nishida”. Philosophie, 79, pp. 43-61.

Stevens, B. (2008). Invitación a la filosofía japonesa. En torno a Nishida. Barcelona: Ed. Bellaterra.

Suzuni, D.T. (1986). Ensayos sobre budismo zen. Segunda serie. Buenos Aires: Kier.

Tremblay, J. (1999a). "Notice introductive à la 'Logique prédicative' de Nishida". Revue Philosophique de Louvain 1, pp. 57-58.

(2007). L'être et l'être-ensemble. L'auto-éveil comme methode philosophieque chez Nishida. Paris: L'Harmattan.

wilkinson, R. (2009). Nishida and Western Philosophy. Aldershot: Ashgate.

zAMBrano, M. (2008. 6a edición). Hacia un saber sobre el alma. Madrid: Alianza.

Zavala, A. J. (1992). "La creación artística como semiosis social en la filosofía de Nishida Kitaro. Un acercamiento”, Relaciones. Vol.13, 52, pp.281-470.

Recibido: 1/04/2018

Aceptado: 22/10/2018

Este trabajo se encuentra bajo una licencia de Creative Commons ReconocimientoNoComercial-SinObraDerivada 4.0 